\title{
Damping Prediction Technique of the Bolted Joint Structure Considering Pretension Force
}

\author{
Delin Sun and Ridong Liao*
}

School of Mechanical Engineering, Beijing Institute of Technology, Beijing 100081, China

\begin{abstract}
At the initial phase of the mechanical product development, it is very important to effectively obtain the modal damping ratio of the bolted joint structure for accurately predicting dynamic response. The energy dissipation has been estimated using a finite element model incorporating the effect of pretension force of the bolted joint. First, the modal damping ratios of the first four modes are extracted by experimental method. Secondly, the lap joint finite element model with pretension force parameter is constructed and based on which, modal analysis of the structure is conducted. The modal shape scaling results are used as the boundary conditions of the finite element model and the energy dissipations and modal damping ratios of the lap joint under different pretension forces are calculated out. By comparing the numerical calculation result and the experimental result, the validation of the damping prediction approach proposed in this paper is proved.
\end{abstract}

Keywords: Bolted joint structure, finite element method, modal damping, pretension force.

\section{INTRODUCTION}

A lot of engineering structures in vehicles and carrier rockets are consisted of the parts fastened by bolted joints. In dynamical environment, the main sources of energy dissipation and structure damping are from interface frictions of the joints [1-3]. Compared to material damping, the damping of the joints is more difficult to predict. In engineering projects, we usually identify the modal damping ratios via modal experiments on the final structure and apply the modal damping ratios to the analysis of structure response.

In 2001, Sandia National Laboratories issued the white paper of "On the development of methodologies for constructing predictive models of structures with joints and interfaces", the main idea of which aims at improving the development procedure of the mechanical products [4]. Namely, the damping prediction should be introduced at the design stage rather than identified at the final structure stage. After that, lots of scholars have been devoted themselves to the studies of the bolted joint energy dissipation and damping prediction technologies.

In experimental research, the classic ones are the big mass device experiment by Sandia and the dumbell joints experiment by Gaul [5-7], the main feature of which is obtaining the tangential damping characteristics of the isolated lap joint by plenty of physical tests.

In calculation and analysis, many scholars use the onedimensional continuum model to study the micro-slip and energy dissipation of the lap joint [8-10]. Lobitz et al. constructed a two-dimensional model of the lap joint and utilized the finite element method to study the energy dissipation characteristics of lap joint [11]. Nanda et al. conducted plenty of researches on the first-order bending damping of the two overlapped steel plates [12]. Hirai et al. constructed the three-dimensional model of the lap joint and studied the energy dissipation and damping characteristics of the bending vibration modes of the lap joint [13]. But he simplified the joint as a rigid element ignoring the effect of the preload on the modal damping.

In order to predict the modal damping of the bolted joint structure, this paper proposes a finite element method which considers the effect of pretension forces on the damping. First, modal experiments under different tightening torques for the lap joint were conducted to extract the modal parameters and verified the effect of the preload on the modal damping. The finite model of the lap joint was constructed and modal analysis of bolted joint structure under preload is conducted. The obtained mode shapes are scaled and then applied to the non-linear finite model as the enforced displacement boundary conditions. Then the energy dissipation of the lap joint and the modal damping ratios are obtained by calculation. At last, by comparing the numerical calculation result and the experimental result, the validation of the damping prediction approach proposed in this paper is ensured.

\section{STUDAY OBJECT}

Fig. (1) shows the geometries and dimensions of the bolted lap joint. The structure is consisted of two long plates and two short plates. This structure is bilaterally symmetrical and each side has six M8 bolts to connect the four parts as a whole. The size of the long plate is $500 \mathrm{~mm} * 100 \mathrm{~mm} * 4 \mathrm{~mm}$ and the short plate is $230 \mathrm{~mm} * 100 \mathrm{~mm} * 4 \mathrm{~mm}$. 


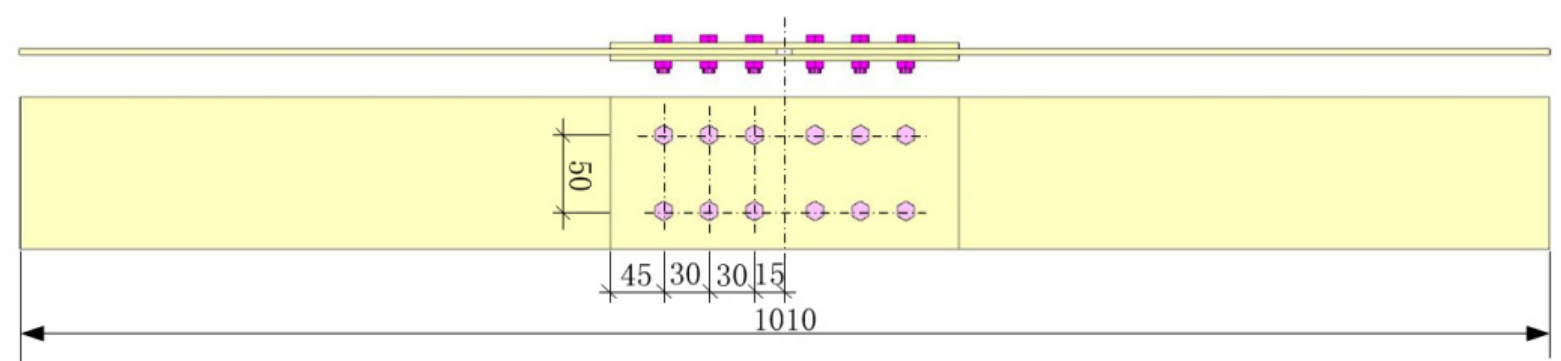

Fig. (1). Geometries and dimensions of the lap joint.

\section{MODAL EXPERIMENTS AND MODAL PARAME- TER IDENTIFICATION}

According to the geometries described in section 2, we manufactured the lap joint and conducted modal experiments on it. There are two purposes of the modal experiments. The first one is to obtain the modal damping ratios under different tightening torques, which will be compared to the numerical results. The second one is to obtain the response of a specific point, which provides a reference displacement when using the enforced displacement method to calculate the energy dissipation.

The devices of the constructed modal experiment platform are shown in Fig. (2) The structure is hung on the elastic rubber ropes to simulate the free-free boundary condition.

Two acceleration sensors are placed at the left end of the lap joint. By roving the hammer, the frequency response function of all points is obtained. The main device and software used in the experiment are listed in Table $\mathbf{1 .}$

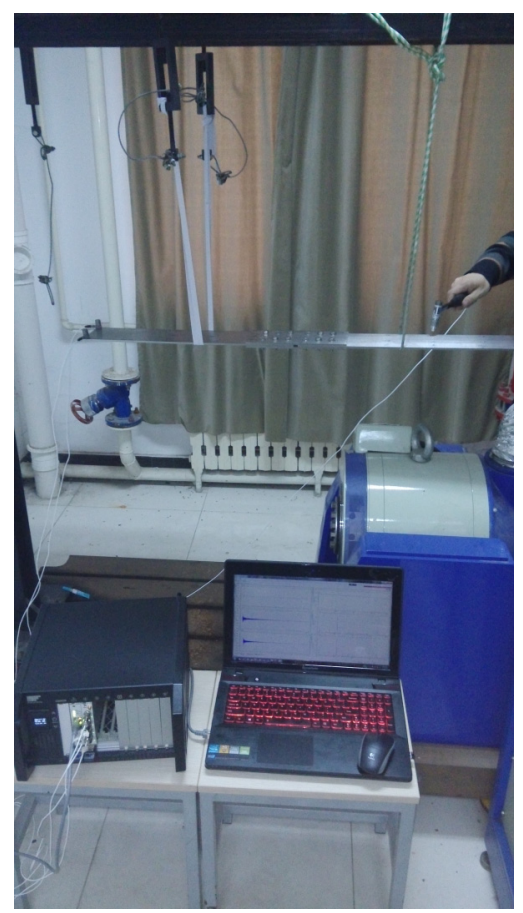

Fig. (2). Site map of the modal experiment.

The frequency response functions under different tightening torques are tested. The tightening torques are respectively $2 \mathrm{Nm}, 4 \mathrm{Nm}$ and $8 \mathrm{Nm}$ regulated by a digital torque wrench. Based on the frequency- response functions, the modal damping ratios are extracted and listed in Table 2.
Table 1. The main device and software used in the modal experiment.

\begin{tabular}{|c|c|c|c|}
\hline $\begin{array}{c}\text { Device } \\
\text { name }\end{array}$ & Model & $\begin{array}{l}\text { Production } \\
\text { place }\end{array}$ & Usage \\
\hline $\begin{array}{l}\text { Test For } \\
\text { I-deas }\end{array}$ & $6 \mathrm{~m} 3$ & $\begin{array}{l}\text { Mayahttt in } \\
\text { Canada }\end{array}$ & $\begin{array}{l}\text { Data acquisition and modal } \\
\text { parameter extraction }\end{array}$ \\
\hline EMX & & $\begin{array}{c}\text { VTI in } \\
\text { America }\end{array}$ & Data acquistion front end \\
\hline Hammer & $086 \mathrm{C} 03$ & $\begin{array}{l}\mathrm{PCB} \text { in } \\
\text { America }\end{array}$ & $\begin{array}{c}\text { Producing excitation sig- } \\
\text { nals }\end{array}$ \\
\hline Force sensor & $208 \mathrm{C} 02$ & $\begin{array}{l}\mathrm{PCB} \text { in } \\
\text { America }\end{array}$ & $\begin{array}{c}\text { Producing acceleration } \\
\text { signals }\end{array}$ \\
\hline $\begin{array}{l}\text { Acceleration } \\
\text { sensor }\end{array}$ & $320 \mathrm{C} 03$ & $\begin{array}{l}\mathrm{PCB} \text { in } \\
\text { America }\end{array}$ & $\begin{array}{c}\text { Producing acceleration } \\
\text { signals }\end{array}$ \\
\hline
\end{tabular}

As it can be seen from Table 2, for the studied lap joint, the changes in tightening torque has little effect on the natural frequencies but has a large effect on the modal damping ratios.

\section{NUMERICAL CALCULATION OF MODAL DAMP- ING RATIOS}

This section constructs the finite element model of the bolted joint structure. The energy dissipation due to interface friction and modal damping ratios are obtained by calculation.

\subsection{Calculation Procedure for Modal Damping}

Fig. (3) shows the calculation procedures for energy dissipation and modal damping ratios. First, a finite element model with contact elements is constructed. Statics calculation is conducted on this model when it is subjected to bolt pretension force, based on which, modal analysis with prestress is conducted and modal results are obtained. The scaling modal shapes are taken as the boundary conditions and applied to the model. The static calculation provides the field output results of the contact zone, such as the contact pressure, contact area and slip displacement. At last, according to the field output result, the energy dissipation due to friction can be calculated and based on which, the modal damping ratios can be estimated.

\subsection{Finite Element Model of the Bolted Joint Structure}

The Finite element model is built in the nonlinear finite element software, Abaqus. The finite element meshes are shown as Fig. (4) In the model, all the elements are 
Table 2. Modal parameters of the lap joint under different tightening torques.

\begin{tabular}{|c|c|c|c|c|c|c|}
\hline Order & \multicolumn{2}{|c|}{$2 \mathrm{Nm}$} & \multicolumn{2}{|c|}{$4 \mathrm{Nm}$} & \multicolumn{2}{|c|}{$8 \mathrm{Nm}$} \\
\hline 1 & 24.9 & 0.65 & 25.0 & 0.41 & 25.0 & 0.27 \\
\hline 2 & 58.1 & 0.35 & 58.2 & 0.16 & 58.2 & 0.08 \\
\hline 4 & 164.5 & 0.70 & 165.6 & 0.44 & 165.9 & 0.42 \\
\hline
\end{tabular}

incompatible mode eight-node brick element, C3D8I [14]. The components material is S30408 stainless steel, the elasticity modulus of which is $193 \mathrm{GPa}$, poisson ratio is 0.3 and density is $7.93 * 103 \mathrm{Kg} / \mathrm{m} 3$.

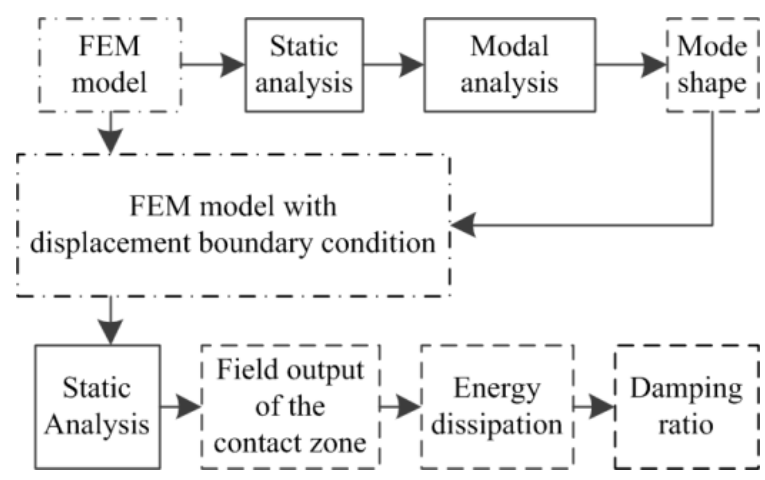

Fig. (3). Flowchart of modal damping prediction.

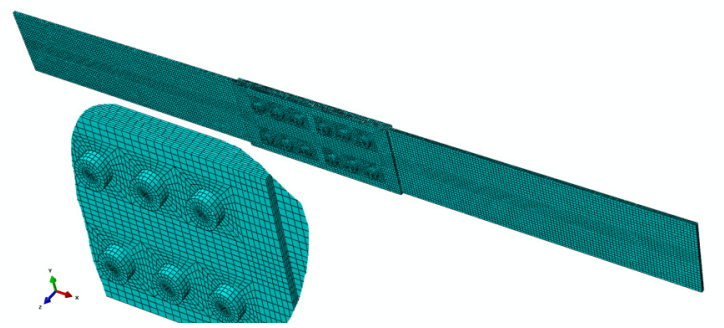

Fig. (4). Finite element mesh of the bolted lap joint.

The interaction surfaces of one bolted joint will form four contact pairs. Penalty method, benefit for convergence calculation, is employed to model the contact normal behavior while penalty method and Coulomb's law are employed to model the tangential behavior. The friction coefficient between the steel plates is measured here in an independent test, by inclining plates under gravitational loading and observing the angle at which sliding starts. The estimated friction coefficient was in this way determined to $\mu=0.13$.

Once the contact mechanics model set up, pretension force should be applied to the bolt. The pretension force value is actually a calculated quantity from the short form torque-preload equation [15]. Bickford states the equation as

$T=k \cdot F_{n} \cdot D$
Where T, k, Fn and D are the input torque, the nut factor, the achieved pretension force and bolt's diameter, respectively. For the case of bolted joints with steel-steel interfaces, $0.15<\mathrm{k}<0.25$. This paper assumes the nut factor is 0.20 . The pre-tightening forces are $1250 \mathrm{~N} 2500 \mathrm{~N}$ and $5000 \mathrm{~N}$ when the tightening torques are $2 \mathrm{Nm} 4 \mathrm{Nm}$ and 8 $\mathrm{Nm}$, respectively.

\subsection{Statics Calculation and Modal Analysis}

In order to consider the effect of pretension force on the modes of the joint, Abaqus performs none-liner statics analysis before performing the modal analysis and obtains the practical contact state, contact stiffness and pre-stress, as well as updates the stiffness matrix $[\mathrm{K}]$ of the system. The following modal analysis utilizes the updated stiffness matrix, ensuring the accuracy of the modal analysis.

The mode shapes of the first four orders are shown in Fig. (5).

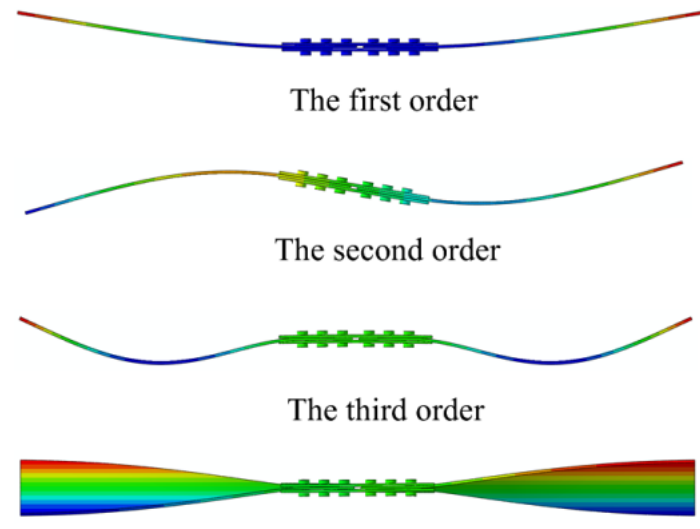

The fourth order

Fig. (5). Mode shapes of the bolted joints structure.

As it can be seen, the first three shapes present bending modes and the fourth shape presents torsional mode. Where, the first mode shape and the third mode shape are symmetric with respect to the central plane vertical to the paper plane. And the second mode shape and the fourth mode shape are anti-symmetric with respect to the central plane.

The mode shape reflects the relative displacement ratios of all freedom degrees of the model. The default normalized maximum displacement obtained by Abaqus is equal to 1 . 


\subsection{Calculation of the Modal Damping Ratio}

\subsubsection{Contact Analysis with Enforced Displacement Boundary Conditions}

Contact analysis is a kind of none-liner calculation, the result of which is related to the magnitude of the load. This paper assumes the bolted joint is within the range of linear vibration. Namely, under small vibration magnitude, the modal damping ratio is none related to the vibration magnitude. In order to obtain a referable enforced displacement, the acceleration response signals at the position shown in Fig. (2) are collected and by filtering around the first order natrual frequency, signals in time domain are obtained. At this time, we convert the maximum value of the acceleration signals to the maximum value of the displacements, which is about $0.6 \mathrm{~mm}$. The applied enforced displacement at this time is defined as the scaling modal shape and the scaling factor $\mathrm{R}$ is 0.6. In the analysis process, the applied enforced displacement increments form 0 to the maximum value, and divided into 50 increments.

The field output results of each increment step are calculated out. Fig. (6) shows the typical results of the contact pressure distribution of the first order and the forth order.

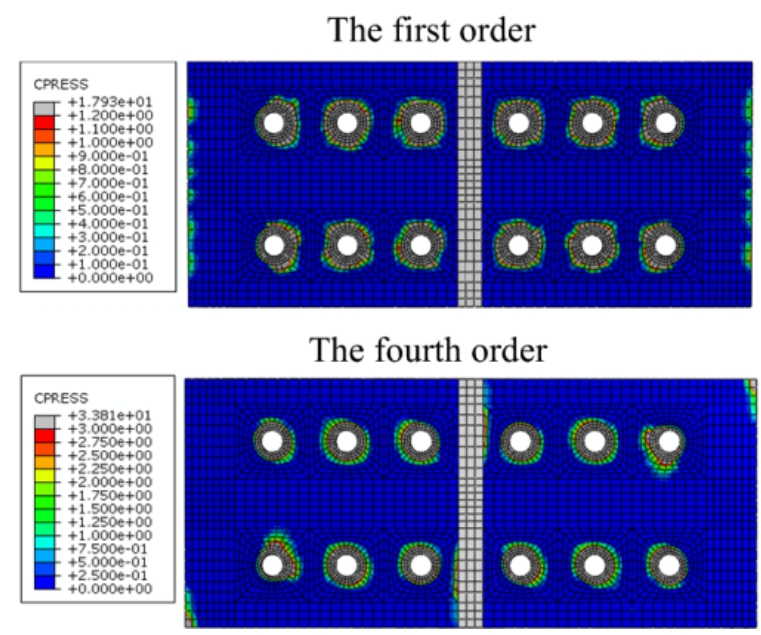

Fig. (6). Contact pressure distribution (upper surface of the two long plates).

As it can be seen, the first mode presents the symmetrical bending shapes so the pressure distribution is also symmetrical. Apart from the zone around bolted joints, the maximum contact pressure lies on the left and right edges of the contact area. And the fourth mode presents torsional mode so the contact pressure distributes in anti-symmetrical form. The maximum contact pressure lies on the outer junction of the crossed edges.

\subsubsection{Calculation of Modal Damping Ratio}

The friction energy dissipation can be calculated by

$$
\Delta W_{r}=\sum_{j=1}^{50} \Delta W_{r}^{j}=\sum_{j=1}^{50} \sum_{i=1}^{N} \mu p_{i}^{j} a_{i}^{j} s_{i}^{j}
$$

Where, $\Delta \mathrm{Wr}$ denotes the total energy dissipation of $1 / 4$ vibration cycle, which is the total energy dissipation of the 50 increment steps. $\Delta \mathrm{Wrj}$ denotes the energy dissipation of the rth mode and $\mathrm{j}$ step. $\mu$ denotes the friction coefficient. pij, aij and sij respectively denote the contact pressure, contact area and slip displacement of rth mode, $i$ element and $j$ step. $\mathrm{N}$ denotes the number of the contact element.

Abaqus provides node slip displacement values in two orthogonal directions, i.e. slip1 and slip2 [14].

$s_{i}^{j}=\sqrt{\left(\operatorname{slip} 1_{i}^{j}\right)^{2}+\left(\operatorname{slip} 2_{i}^{j}\right)^{2}}$

The modal damping ratios are calculated by

$$
\zeta_{r}=\frac{\Delta W_{r}}{\pi E_{r}}
$$

where, $\zeta \mathrm{r}$ denotes the modal damping ratio of the rth mode. Er denotes the modal kinetic energy of the rth mode, which is defined by formula (5) [16].

$$
E_{r}=\frac{1}{2} R_{r}^{2} \omega_{r}^{2}\left\{\varphi_{r}\right\}^{T}[M]\left\{\varphi_{r}\right\}
$$

where, $\{\varphi r\}$ denotes the modal shape of the rth mode. $[\mathrm{M}]$ denotes the mass matrix of the finite element model.

The modal damping ratios under different torque forces of the former four orders are calculated. In order to comparison, the modal damping rations respectively obtained by calculation and experiment are put together in Fig. (7).

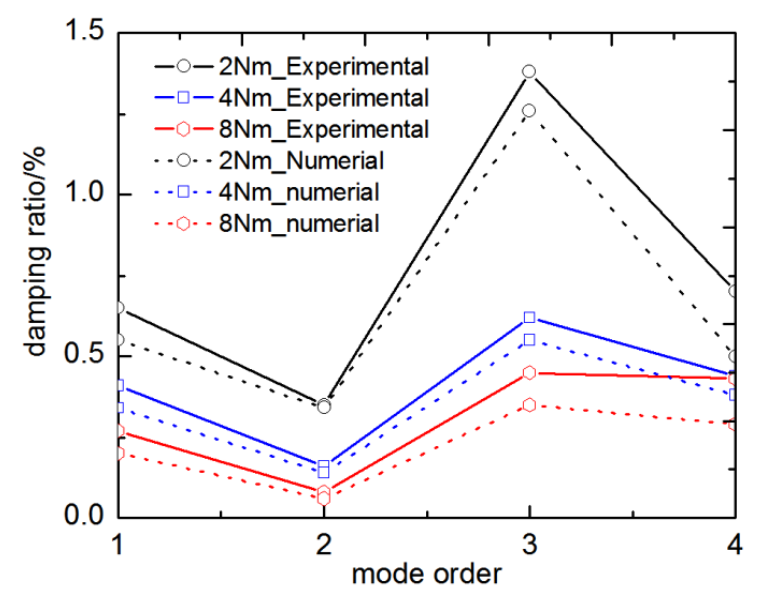

Fig. (7). A comparison of modal damping ratios under different torque forces between calculation and experiment.

As it can be seen, on the overall trend, the modal damping ratios obtained by calculation and experiment are consistent, which indicates the reasonability of the mothod. Secondly, whether from the experiment result or the simulation result, the modal damping ratio decreases with the increasing of the tightening torques. Thirdly, the calculation result is lower than the experiment result. The reason may be the energy dissipation of the hanging ropes at experiment increases the structure damping ration or the nut factor is not given by a sufficiently accurate value, etc.

\section{CONCLUSION}

This paper proposes a method of predicting modal damping ratios of the bolted joint structure by using the finite element model. The method incorporates the pretension 
force into the finite element model and calculates out the modal damping ratios under different pretension forces. The calculation result agreed well with the experiment result, which proved the conclusion that the modal damping ratio was negatively correlated to the pretension force, as well as the reasonability of the modal damping prediction method.

\section{CONFLICT OF INTEREST}

The authors confirm that this article content has no conflicts of interest.

\section{ACKNOWLEDGEMENTS}

This work is supported by defense pre-research project of China (No.104010205).

\section{REFERENCES}

C. F. Beards, "The damping of structural vibration by controlled interface slip in joints," Journal of Vibration, Acoustics, Stress analysis, Reliability Design, vol. 105, pp. 369-373, 1983.

[2] S. J. I. Walker, G. S. Aglietti, P. A. "Cunningham study of joint damping in metal plates," Journal of Acta Astronautica, vol. 65, no.1-2, pp. 184-191, 2009

[3] M. Iranzad, and H. Ahmadian, "Identification of nonlinear bolted lap joint models," Journal of Computers \& Structures, vol. 96-97: pp. 1-8. 2012.

[4] D. L. Gregory, D. R. Martinez, "On the development of methodologies for constructing predictive models of structures with joints and interfaces," Journal of Sandia National Laboratories, Technical Report, No. SAND2001-0003P, 2001.

[5] M. J. Starr, and D. J. Segalman, "An empirical relationship for extrapolating sparse experimental lap joint data," Journal of Journal of Applied Mechanics, vol. 78, no. 6, pp. 061002, 2011.
[6] R. L. Mayes, “A Feasibility Study for Experimentally Determining Dynamic Force Distribution in a Lap Joint," Sandia National Laboratories (SNL-NM), Albuquerque, NM (United States), 2013.

[7] S. Bograd, P. Reuss, A. Schmidt, L. Gaul, and M. Mayer, "Modeling the dynamics of mechanical joints," Journal of Mechanical Systems and Signal Processing, vol. 25, no. 8, pp. 2801-2826, 2011.

[8] H. Wentzel, and M. Olsson, "Influence from Contact Pressure Distribution on Energy Dissipation in Bolted Joints," SAE Technical Paper, US, Canada, 2006.

[9] Y. Song, D. M. McFarland, L. A. Bergman, and A. F. Vakakis, "Effect of pressure distribution on energy dissipation in a mechanical lap joint," Journal of Aiaa Journal, vol. 43, no. 2, pp. 420 - 425, 2005.

[10] H. Xiao, Y. Shao, and J. Xu. "Investigation into the energy dissipation of a lap joint using the one-dimensional microslip friction model," Journal of European Journal of Mechanics - A/Solids, vol. 43, pp. 1-8, 2014.

[11] D. W. Lobitz, D. L. Gregory, and D. O. Smallwood, "Comparison of finite element predictions to measurements from the sandia microslip experiment," Journal of Sandia National Laboratories, Albuquerque, NM, Technical Report No. SAND2000-2799C, 2000.

[12] B. K. Nanda, "Study of the effect of bolt diameter and washer on damping in layered and jointed structures," Journal of Journal of Sound and Vibration, vol. 290, no. 3, pp. 1290 - 1314, 2006.

[13] T. Hirai, F. Kuratani, K. Koide, and I. Kido, "A simplified method for estimating damping of joined plate structures with partial overlap region," Journal of Transactions of the JSME (in Japanese), vol.80, no. 812, 2014. (TRANS0075)

[14] Abaqus-Inc. Abaqus User Manual, Version 6.10. Version 6.10 ed 2010

[15] J. Bickford. Handbook of Bolts and Bolted Joints. CRC Press, Boca Raton, 1998.

[16] H. Wentzel, and M. Olsson, "Numerical prediction of damping in structures with frictional joints," Journal of International Journal of Vehicle Noise and Vibration, vol. 2, no. 2, pp. 125-142, 2006.

Received: January 05, 2015

(C) Sun and Liao; Licensee Bentham Open.

This is an open access article licensed under the terms of the (https://creativecommons.org/licenses/by/4.0/legalcode), which permits unrestricted, noncommercial use, distribution and reproduction in any medium, provided the work is properly cited. 